\title{
QUASI-CRYSTALLINE ALLOYS-FILLERS FOR COMPOSITE LAYERS PRODUCED USING METHOD OF FURNACE SURFACING
}

\author{
E.V. SUKHOVAYA \\ O. Gonchar Dnepropetrovsk National University \\ 72 Gagarin Ave., 49010, Dnepropetrovsk, Ukraine. E-mail: sukhovaya@ukr.net
}

\begin{abstract}
Structure and properties of macro-heterogeneous composite layers produced using method of furnace surfacing were investigated. As the fillers the quasi-crystalline alloys $\mathrm{Al}-\mathrm{Cu}-\mathrm{Fe}, \mathrm{Al}-\mathrm{Co}-\mathrm{Cu}$ and $\mathrm{Al}-\mathrm{Co}-\mathrm{Ni}$ were used. As the bonds the alloys based on aluminium and copper were used. It was shown that the method of furnace surfacing allows obtaining the content of quasi-crystalline icosahedral $\psi$-phase of not less than $30 \mathrm{vol} . \%$ in the structure of composite layers strengthened by $\mathrm{Al}-\mathrm{Cu}-\mathrm{Fe}$ alloy-filler, and the content of quasi-crystalline decagonal D-phase of up to $55 \mathrm{vol} \% \%$ in the structure of composite layers with alloys-fillers $\mathrm{Al}-\mathrm{Co}^{-} \mathrm{Cu}$ and $\mathrm{Al}-\mathrm{Co}-\mathrm{Ni}$. The regularities of formation of interfaces between filler and bond during surfacing are explained by realization of solution-diffusive mechanism of processes of contact interaction. The primary dissolution of crystalline phases of alloys-fillers was established, which leads to penetration of molten bonds inside the filler along the boundaries of crystals of the quasi-crystalline phase. The increase in intensity of processes of dissolution of filler crystalline phases in use for surfacing of $\mathrm{Cu}$-based bonds results in their complete recrystallization in the process of cooling at retaining not-dissolved inclusions of quasi-crystalline phase in the structure of composite layers. To produce the surfaced layers operating under the conditions of dry friction, the composite material based on tin bronze Br.Ots 10-2 armored by the $\mathrm{Al}-\mathrm{Co}-\mathrm{Ni}$ alloy-filler was recommended. The composite material with bond of brass L62 and alloy-filler $\mathrm{Al}-\mathrm{Co}-\mathrm{Cu}$ has the maximum resistance in oxide media. 11 Ref., 1 Table, 4 Figures.
\end{abstract}

Keywords: composite layer, furnace surfacing, quasi-crystalline phase, interphase interaction, dissolution, corrosion resistance in oxide media, tribotechnical properties

The efficient method to increase the life of parts operating under the conditions of intensive abrasive and gas-abrasive wear is the furnace surfacing which was developed by the associates of the E.O. Paton Electric Welding Institute [1]. It consists in impregnation of preliminary formed powders of refractory alloys-fillers by fusible bond in the process of heating in furnace. The method allows regulating the cooling rate during crystallziaiton, and under the condition of wetting it provides a high quality of surfaced composite layers and bimetal joints. Besides, using this method the service life of such critical parts of metallurgical equipment as valves, small and large cones of charging units of blast furnaces is 3-15 times increased [2]. To perform the process, the special expensive equipment is not required and due to the so-called autovacuum effect the limited access of oxygen to the surfaces of contacting phases during surfacing is provided.

The best operation characteristics are observed in the surfaced composite alloys, where in capacity of alloys-fillers the tungsten carbides [3] in

(C) E.V. SUKHOVAYA, 2014 cast (relite) and baked form and also as cermet alloys with a cobalt bond (of type VK) are used. To manufacture the composite layers without the content of scarce and expensive tungsten carbides, the chromium carbides $\mathrm{Cr}_{3} \mathrm{C}_{2}$ and chromium carbides with nickel bond KKhN5, KKhN10 and KKhN15 are applied [4]. In the composition of composite layers alongside with the carbides the borides of refractory metals are used, which have a high heat resistance, hardness and abrasive wear resistance, that promotes their sufficiently wide application in industry.

In works [5, 6] the possibility of replacement of $\mathrm{W}$-containing hard alloys, used in manufacture of composite alloys, by the following borides of metals of IVa-VIa subgroups: $\mathrm{TiB}_{2}, \mathrm{ZrB}_{2}, \mathrm{HfB}_{2}$, $\mathrm{FeB}_{2}, \mathrm{TaB}_{2}, \mathrm{CrB}_{2}, \mathrm{Mo}_{2} \mathrm{~B}_{5}, \mathrm{~W}_{2} \mathrm{~B}_{5}$, was studied. However, among all the studied materials the most prospective, in opinion of the authors of [7], are the surfaced composite layers containing fillers of binary $\mathrm{Ti}-\mathrm{Cr}$ borides $(\mathrm{Ti}, \mathrm{Cr}) \mathrm{B}_{2}$. This boride alongside with high strength properties has the lower brittleness as compared to pure borides, and as to the wear resistance it is close to hard alloys.

The field of application of the method of furnace surfacing to produce the composite layers can be sufficiently expanded due to application 
of quasi-crystalline alloys-fillers in their composition, having high hardness, low friction coefficient, increased corrosion resistance [8]. At the combination of quasi-crystals with ductile metallic matrix it is possible to overcome such their main disadvantage as brittleness, which limits the application of quasi-crystals in the products of modern engineering.

As far as information concerning the use of the method of furnace surfacing to produce surfaced composite layers, strengthened by quasicrystalline alloys-fillers, is absent, in the present work the results of investigation of structure and properties of this class of surfacing materials, intended to strengthen and restore the parts operating under the conditions of dry friction and oxide environments effect, are given.

Methods of experiment. The alloys-fillers $\mathrm{Al}-$ $\mathrm{Cu}-\mathrm{Fe}, \mathrm{Al}-\mathrm{Co}^{-} \mathrm{Cu}$ and $\mathrm{Al}-\mathrm{Co}-\mathrm{Ni}$ were melted in Tamman furnace from chemically pure elements. The cooling rate of the alloys was $50 \mathrm{~K} / \mathrm{s}$. The composition of alloys-fillers was selected so that to provide the content of quasi-crystalline phase in structure of not less than $50 \%$ of volume. The content of elements was controlled using the methods of chemical and spectral X-ray fluores- cent analyses. The produced alloys were crushed in the hammer mill to the fractions of $0.2-$ $2.0 \mathrm{~mm}$. The impregnation was performed by alloys-bonds on aluminium or copper base at the temperature, which by $50-100 \mathrm{~K}$ exceeded the melting temperature of a bond alloy. The duration of isothermal soaking during surfacing varied within the limits of 30-60 min. The structure of surfaced composite layers was investigated using the methods of quantitative metallography, scanning electron microscopy, X-ray diffraction analysis and X-ray spectral microanalysis. The rate of corrosion of composite layers in the oxide media was determined using gravimetric method. The measurements were carried out every hour at the room temperature during $4 \mathrm{~h}$. The tribotechnical tests were performed according to the shaft-bushing scheme under the conditions of friction without lubrication on steel 45 at sliding speed of $20 \mathrm{~m} / \mathrm{s}$ and loading of $4 \mathrm{MPa}$ in the machine manufactured according to the designs [9].

Results of experiment. The alloy-filler Al$\mathrm{Cu}-\mathrm{Fe}$ has a double-phase structure consisting of quasi-crystalline icosahedral $\psi$-phase of $\mathrm{Al}_{63} \mathrm{Cu}_{25} \mathrm{Fe}_{12}$ composition and crystalline cubic
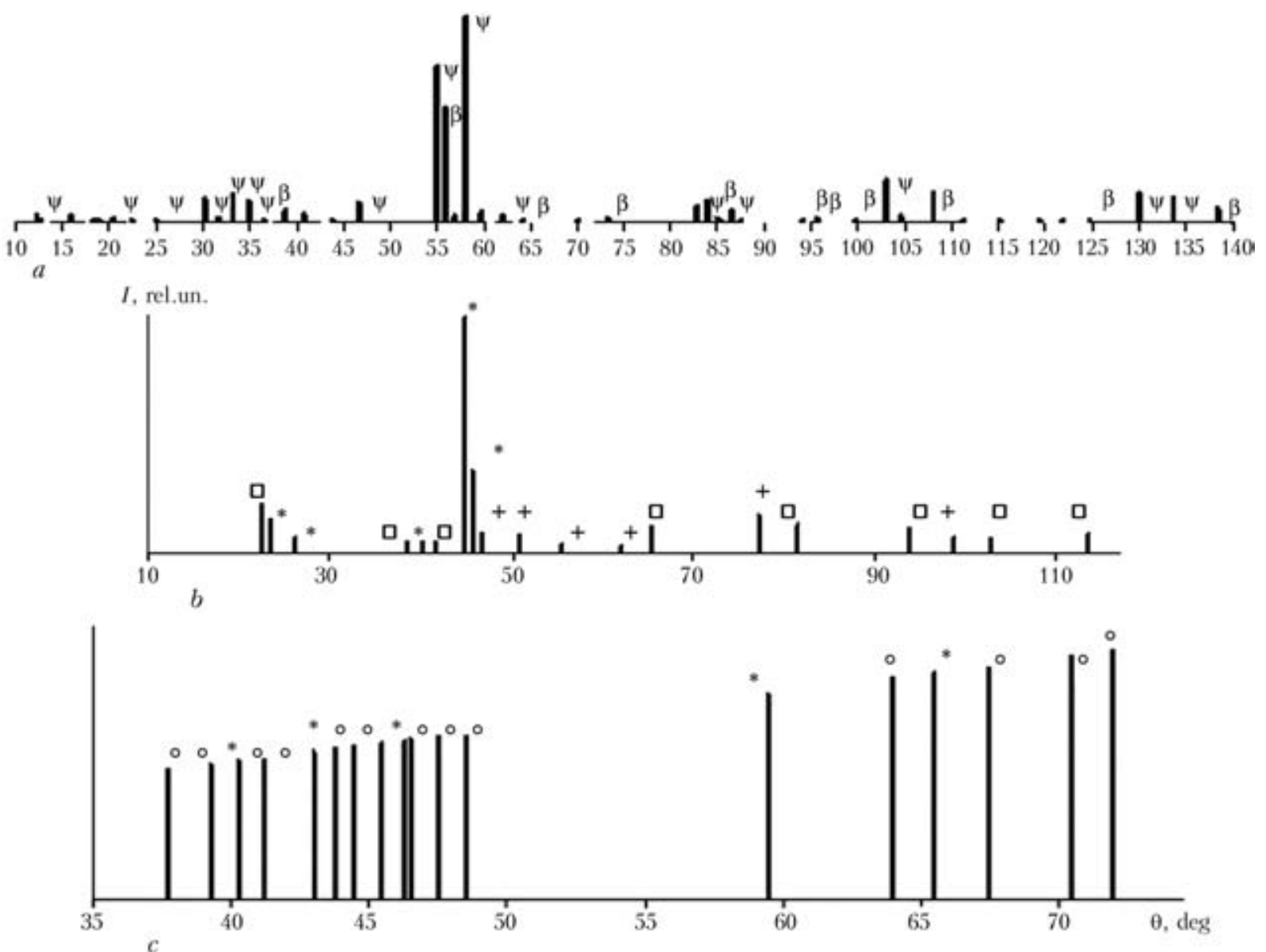

Figure 1. Marked X-ray photographs ( $\mathrm{Fe}-K_{\alpha}$-radiation) of alloys: $a-\mathrm{Al}-\mathrm{Cu}-\mathrm{Fe} ; b-\mathrm{Al}-\mathrm{Co}-\mathrm{Cu} ; c-\mathrm{Al}-\mathrm{Co}-\mathrm{Ni}$; * - D-phase; $\square-\mathrm{Al}_{4}(\mathrm{Co}, \mathrm{Cu})_{3} ;+-\mathrm{Al}_{3}(\mathrm{Co}, \mathrm{Cu})_{2} ; \mathrm{O}-\mathrm{Al}_{9}(\mathrm{Co}, \mathrm{Ni})_{2}$ 


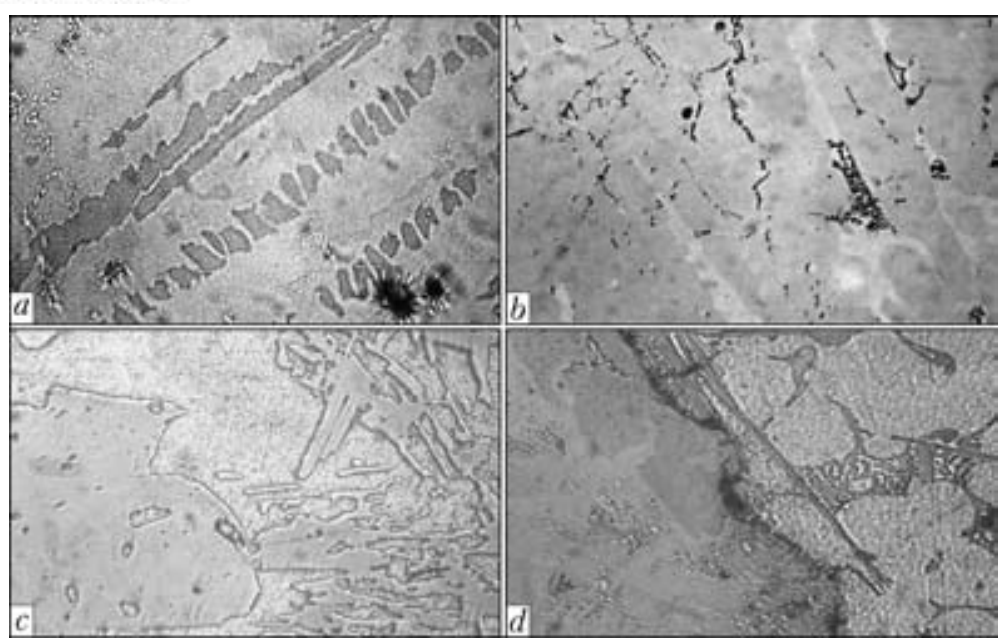

Figure 2. Microstructure of composite materials on base of aluminium alloys strengthened by Al-Cu-Fe alloy-filler: $a-$ initial alloy-filler; $b$ - alloy-bond $(\mathrm{Al}-6 \% \mathrm{Mg}) ; c-$ alloy-bond $(\mathrm{Al}-5 \% \mathrm{Cu}) ; d-$ alloy-bond (commercial $\mathrm{Al})(a$, $b, d-\times 800 ; c-\times 1000)$

phase FeAl ( $\beta$-phase) (Figures 1, $a$ and 2,a). The morphology of $\psi$-phase is defined by the presence of axis of symmetry of the fifth order and quasi-periodical long-range order in three directions [8]. The volumetric content of this phase in the structure of filler reaches $50 \%$.

After impregnation by the bond alloys based on aluminium the uniform distribution of particles of the filler across the section of composite material is observed (Figure 2, $b-d$ ). The content of alloy-filler amounts to $60-65 \%$ and that of quasi-crystalline phase is about $35 \%$ of material volume. At the interfaces between the filler and molten bonds the processes of contact interaction are running during surfacing, accompanied mainly by dissolution of $\beta$-phase of the filler. The quasi-crystalline $\psi$-phase is retained in the structure almost without changes. At next cooling the zones of contact interaction of a solution-diffusion type are formed at the interfaces due to recrystallization of dissolved regions of the filler. On the side of filler a layer is appeared, the composition of which differs from the initial composition by an increased $\mathrm{Al}$ content and lower $\mathrm{Cu}$ and Fe content. On the side of solidified Al-based alloys-bonds the copper and iron are present near the interface. The measurement of width of con- tact interaction zones shows the intensity of processes of dissolution of crystalline phases of the alloy-filler in molten alloy-bond is decreased depending on its composition in the following row: $\mathrm{Al} \rightarrow(\mathrm{Al}-\mathrm{Mg}) \rightarrow(\mathrm{Al}-\mathrm{Cu}) \rightarrow(\mathrm{Al}-\mathrm{Si})$. In the same sequence the porosity of surfaced composite layers is increased, reaching the maximum value of about $40 \mathrm{vol} . \%$, when the alloy-bond $\mathrm{Al}-\mathrm{Si}$ is applied.

With account for obtained results the specimens, surfaced by composite material $\mathrm{Al}-\mathrm{Cu}^{-}$ $\mathrm{Fe} / \mathrm{Al}$, in structure of which the content of pores does not exceed 3 vol.\%, were selected for next tests. The corrosion rate of this material has the least values in solutions $5 n \cdot \mathrm{H}_{3} \mathrm{PO}_{4}$ and $1 \mathrm{n} \cdot \mathrm{HCL}$ (Table). Coefficient of friction is within the ranges of $0.17-0.19$.

Before surfacing three phases are present in the structure of alloy-filler $\mathrm{Al}-\mathrm{Co}-\mathrm{Cu}$ : one quasicrystalline and two crystalline (Figures $1, b$ and $3, a)$. Crystals of crystalline cubic phase AlCo ( $\beta$-phase) are precipitated firstly from liquid (L). Then, quasi-crystalline decagonal D-phase, having stoichiometric composition $\mathrm{Al}_{63} \mathrm{Co}_{24} \mathrm{Cu}_{13}$, is formed by peritectic reaction $\mathrm{L}+\beta \rightarrow \mathrm{D}$. Its prismatic crystals are growing mainly in the direction, parallel to axis of symmetry of the tenth

Properties of composite materials strengthened by quasi-crystalline alloys-fillers

\begin{tabular}{|c|c|c|c|c|c|c|c|}
\hline \multirow{2}{*}{ Alloy-filler } & \multirow{2}{*}{ Alloy-bond } & \multirow{2}{*}{$\begin{array}{l}\text { Coefficient of } \\
\quad \text { friction }\end{array}$} & \multirow{2}{*}{$\begin{array}{c}\text { Wear intensity, } \\
\mu \mathrm{m} / \mathrm{km}\end{array}$} & \multicolumn{4}{|c|}{ Corrosion rate, $\mathrm{g} /\left(\mathrm{m}^{2} \cdot \mathrm{h}\right)$} \\
\hline & & & & $0.5 \mathrm{n} \cdot \mathrm{H}_{2} \mathrm{SO}_{4}$ & $5 \mathrm{n} \cdot \mathrm{H}_{3} \mathrm{PO}_{4}$ & $0.8 \mathrm{n} \cdot \mathrm{HNO}_{3}$ & $1 \mathrm{n} \cdot \mathrm{HCl}$ \\
\hline $\mathrm{Al}-\mathrm{Cu}-\mathrm{Fe}$ & $\mathrm{Al}$ (commercial) & 0.18 & 15.3 & $2.67 \pm 0.03$ & $0.88 \pm 0.05$ & $15.43 \pm 0.05$ & $0.98 \pm 0.02$ \\
\hline \multirow[t]{2}{*}{$\mathrm{Al}-\mathrm{Co}-\mathrm{Cu}$} & L62 & 0.09 & 7.9 & $1.95 \pm 0.06$ & $0.43 \pm 0.04$ & $9.92 \pm 0.03$ & $0.79 \pm 0.01$ \\
\hline & Br.Ots $10-2$ & 0.06 & 4.3 & $2.14 \pm 0.05$ & $0.60 \pm 0.07$ & $13.28 \pm 0.04$ & $0.84 \pm 0.03$ \\
\hline \multirow[t]{2}{*}{$\mathrm{Al}-\mathrm{Co}-\mathrm{Ni}$} & L62 & 0.08 & 7.3 & $2.42 \pm 0.01$ & $0.52 \pm 0.04$ & $13.11 \pm 0.08$ & $0.89 \pm 0.03$ \\
\hline & Br.Ots $10-2$ & 0.04 & 3.0 & $2.55 \pm 0.03$ & $0.73 \pm 0.05$ & $13.90 \pm 0.05$ & $0.93 \pm 0.02$ \\
\hline
\end{tabular}



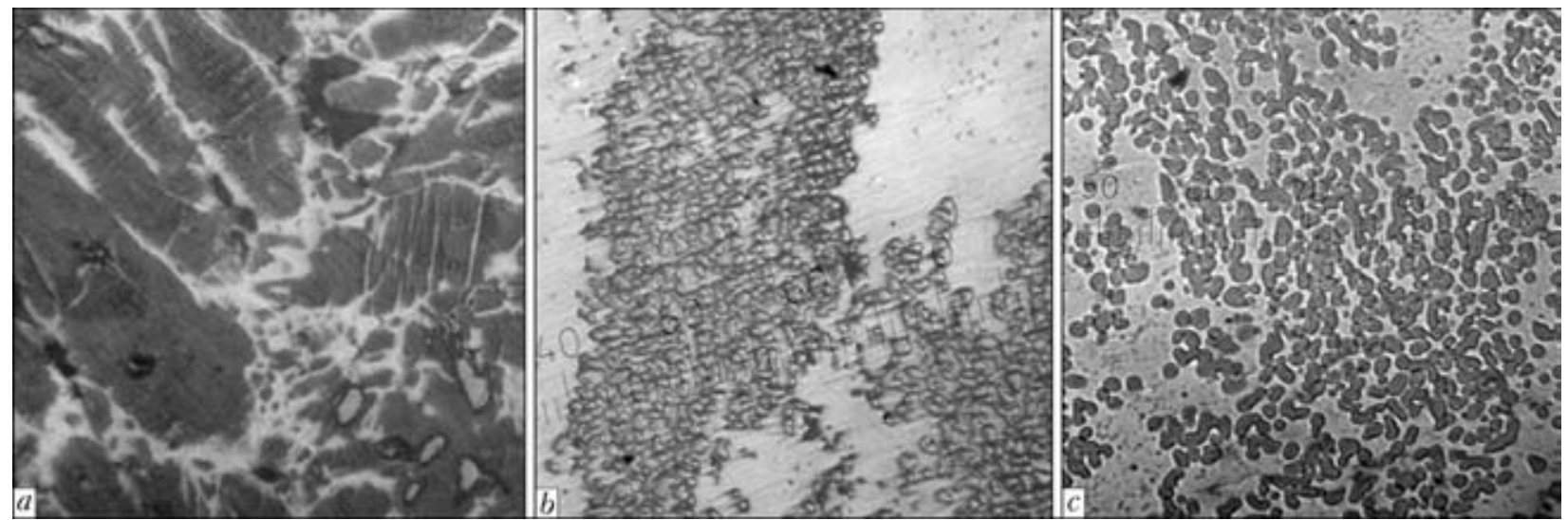

Figure 3. Microstructure $(\times 800)$ of composite materials on base of copper alloys strengthened by $\mathrm{Al}-\mathrm{Co}-\mathrm{Cu}$ alloy-filler: $a$ - initial alloy-filler; $b$ - alloy-bond L62; $c$ - alloy-bond Br.Ots 10-2

order, along which the D-phase has a periodic arrangement of atoms [10]. Quasi-periodic longrange order is observed in perpendicular plane. Volumetric content of quasi-crystalline phase in filler structure is about $80 \%$. Crystals of hexagonal phase $\mathrm{Al}_{3}(\mathrm{Cu}, \mathrm{Co})_{2}$ (H-phase) are formed along the boundaries of quasi-crystalline phase.

Taking into account the stability of D-phase up to $1250 \mathrm{~K}$, the following Cu-based alloysbonds on were used for impregnation of particles of $\mathrm{Al}-\mathrm{Cu}-\mathrm{Co}$ alloy-filler: brass $\mathrm{L} 62$ and tin bronze Br.Ots 10-2. The peculiar features of structure of produced composite layers are defined by the processes of primary dissolution of crystalline H-phase of the filler. Therefore, during impregnation the molten alloys-bonds penetrate inside the filler along the boundaries of quasi-crystalline phase across the section of strengthening particles (Figure 3, b,c). This leads to a partial dissolution of D-phase, which is testified by change in its morphology from faceted to rounded one. As a result, separate inclusions of D-phase in Cu-based matrix are observed.

Due to dissolution of crystalline phases of alloy-filler in molten brass, its as-solidified composition near the interface with filler is differed from initial composition by the presence of $\mathrm{Al}$ and decrease in $\mathrm{Cu}$ and $\mathrm{Zn}$ content (see Figure 3, b). $\mathrm{Al}, \mathrm{Co}, \mathrm{Zn}$ and $\mathrm{Cu}$ were observed in matrix interlayers between the crystals of D-phase. The growing intensity of processes of dissolution of filler in case of impregnation by bronze bond, as compared to brass one, leads to the violation of macro-heterogeneous constitution of surfaced composite layer. As a consequence, the non-dissolved regions of quasi-crystalline D-phase are almost uniformly distributed in the volume of the solidified bond (Figure 3,c). Aluminium and traces of cobalt were observed in it, except the initial components. At the periphery of inclusions of D-phase the $\mathrm{Co}$ and $\mathrm{Cu}$ content are somewhat increased, that is caused by recrystallization of non-dissolved components in bond during cooling on the surface of this phase.

Results of tests show that the corrosion rate in acid media is decreased in use of a brass bond for impregnation of alloy-filler $\mathrm{Al}-\mathrm{Co}-\mathrm{Cu}$ (see the Table), while in case of bronze bond applying the reduction of coefficient of friction and wear intensity is provided.

Alloy-filler $\mathrm{Al}-\mathrm{Co}^{-\mathrm{Ni}}$ has a two-phase structure before surfacing (Figures $1, b$ and $4, a$ ), which is mainly formed by quasi-crystalline
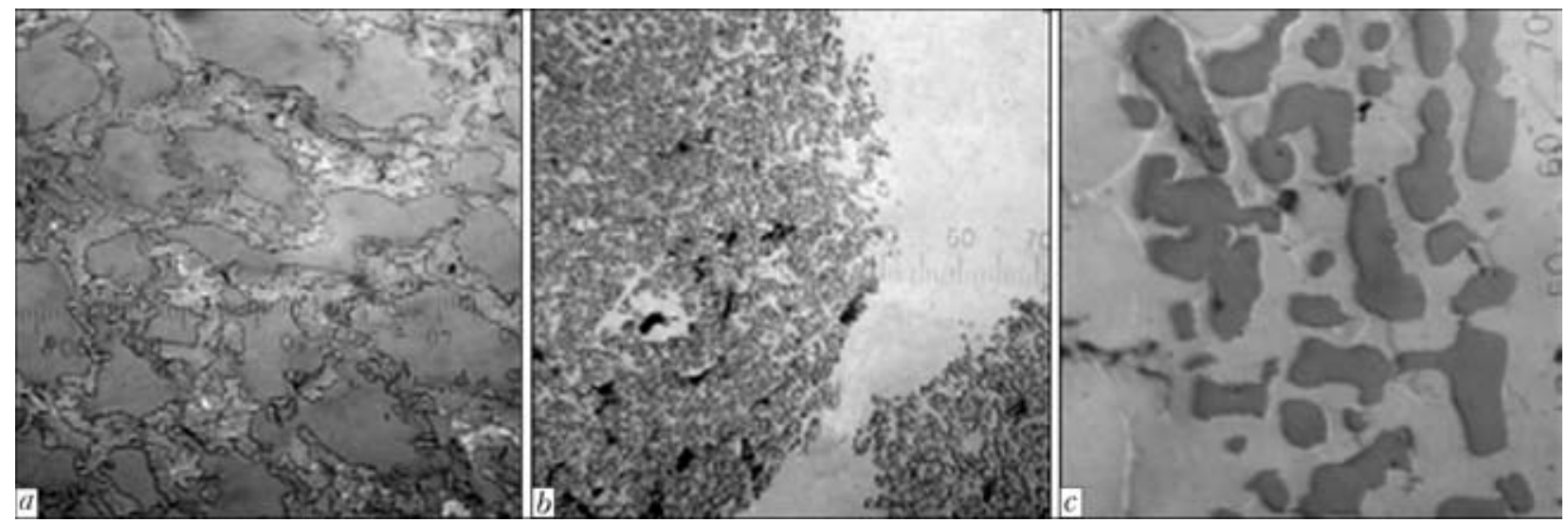

Figure 4. Microstructure of composite materials on base of copper alloys strengthened by Al-Co-Ni alloy-filler: $a-$ initial alloy-filler; $b$ - alloy-bond L62; $c-$ alloy-bond Br.Ots 10-2 $(a, b-\times 800 ; c-\times 2000)$ 
decagonal D-phase, occupying more than $85 \%$ of alloy volume. D-phase is crystallized directly from liquid and has stoichiometric composition $\mathrm{Al}_{69} \mathrm{Co}_{21} \mathrm{Ni}_{10}$. Moreover, there is phase $\mathrm{Al}_{9}(\mathrm{Co}$, $\mathrm{Ni})_{2}$ in structure, formed by peritectic reaction $\mathrm{L}+\mathrm{D} \rightarrow \mathrm{Al}_{9}(\mathrm{Co}, \mathrm{Ni})_{2}[11]$, which has a variable composition, that can be connected with a different degree of completion of the peritectic reaction.

During furnace surfacing the impregnation of particles of $\mathrm{Al}-\mathrm{Co}^{-} \mathrm{Ni}$ alloy-filler by copper bonds of the above-mentioned composition is accompanied by their penetration along the grain boundaries of quasi-crystalline D-phase due to more intensive dissolution of crystalline phase $\mathrm{Al}_{9}(\mathrm{Co}, \mathrm{Ni})_{2}$. As a result the structure of surfaced composite layers has separate rounded inclusions of D-phase, located after impregnation by a brass bond in the places of location of initial filler particles, and distributed uniformly in matrix after impregnation by a bronze bond (Figure $4, b$, $c)$. This proves about the high intensity of processes of contact interaction between the filler and molten bond in surfacing at the second case.

As compared with surfaced composite layers, strengthened by alloy-filler $\mathrm{Al}-\mathrm{Co}-\mathrm{Cu}$, the content of quasi-crystalline phase in composite layers with alloys-fillers $\mathrm{Al}-\mathrm{Co}-\mathrm{Ni}$ is by $15 \%$ higher on average and reaches $55 \%$. The obtained result can be explained by the higher resistance to the effect of molten bond of primary D-phase of $\mathrm{Al}_{69} \mathrm{Co}_{21} \mathrm{Ni}_{10}$ composition, as compared with $\mathrm{D}$ phase of $\mathrm{Al}_{63} \mathrm{Co}_{24} \mathrm{Cu}_{13}$ composition formed by peritectic reaction. As a consequence, the content of components of $\mathrm{Al}-\mathrm{Co}-\mathrm{Ni}$ alloy-filler in $\mathrm{Cu}^{-}$ based solidified bonds is lower than in surfaced layers strengthened by the alloy-filler $\mathrm{Al}-\mathrm{Co}^{-}$ $\mathrm{Cu}$. Due to increase in content of quasi-crystalline phase, the minimum values of coefficient of friction and intensity of wear of composite layers with $\mathrm{Al}-\mathrm{Co}^{-} \mathrm{Ni}$ alloy-filler are reached (see the Table).

\section{Conclusion}

The application of method of furnace surfacing makes it possible to produce the surfaced composite layers on aluminium and copper base, strengthened by quasi-crystalline alloys-fillers
$\mathrm{Al}-\mathrm{Cu}-\mathrm{Fe}, \mathrm{Al}-\mathrm{Co}^{-} \mathrm{Cu}$ and $\mathrm{Al}-\mathrm{Co}-\mathrm{Ni}$. During surfacing in molten bonds the crystalline phases of alloys-fillers are mainly dissolved. In spite of a partial dissolution of quasi-crystalline phase, its content in structure of composite alloys reaches $30-55 \%$ of their volume depending on the filler composition.

The surfaced composite layers, strengthened by quasi-crystalline alloys-fillers, are characterized by the corrosion resistance in acid solutions and high tribotechnical properties. These characteristics are correlated with content of quasi-crystalline phases, reaching the maximum values in case of composite layers of $\mathrm{L} 62 / \mathrm{Al}-$ $\mathrm{Co}^{-} \mathrm{Cu}$ and Br.Ots $10-2 / \mathrm{Al}-\mathrm{Co}-\mathrm{Ni}$ compositions, respectively.

1. Netesa, I.V., Dudko, D.A., Maksimovich, B.I. et al. Method of wear-resistant surfacing. USSR author's cert. 562393. Int. Cl. B 23 K 9/04, B 22 D $19 / 08$. Fil. 18.07.1975. Publ. 08.06.1977.

2. Danilov, L.I., Rovenskykh, F.M. (1979) Surfacing of parts of charging devices of blast furnace by composite alloy. Metallurg, 1, 12-15.

3. Dudko, D.A., Maksimovich, B.I., Zelenin, V.I. et al. (1975) Wettability of wear-resistant components of composite alloys by ligaments on copper-nickel-manganese base. Avtomatich. Svarka, 5, 5-6.

4. Dudko, D.A., Zelenin, V.I., Netesa, I.V. et al. (1977) Novel wear-resistant surfacing composite alloys. In: Wear-resistant surfacing materials on the base of refractory compounds. Kiev: Naukova Dumka, 3-5.

5. Bystrov, V.A., Bystrov, A.V., Dzodziev, G.T. et al (1979) Investigation of properties of composite alloys on carbide titanium base. In: Properties and tests of deposited metal. Kiev: PWI, 131-135.

6. Borovikova, M.S. (1980) Main principles of contact interaction of refractory borides with some nontransition metals. In: Phase interphases and their properties. Kiev: IAM, 72-79.

7. Samsonov, G.V., Panasyuk, A.D., Borovikova, M.S. (1973) Interaction of refractory borides with liquid metals of iron family. Poroshk. Metallurgiya, 6, 51-57.

8. Huttunen-Saarivirta, E. (2004) Microstructure, fabrication and properties of quasicrystalline $\mathrm{Al}-\mathrm{Cu}-\mathrm{Fe}$ alloys: A review. J. Alloys Comp., 363, 150-174.

9. Mamykin, E.T., Kovpak, M.K., Yuga, A.I. et al. (1973) Complex of machines and procedure for determination of antifriction properties of materials in sliding friction. Poroshk. Metallurgiya, 1, 67-72.

10. Tsai, A.-P., Inoue, A., Masumoto, T. (1989) A stable decagonal quasicrystal in the $\mathrm{Al}-\mathrm{Cu}-\mathrm{Co}$ system. $M a-$ ter. Transact. of JIM, 30(4), 300-304.

11. Godecke, T., Ellner, M. (1996) Phase equilibria in the aluminum-rich portion of the binary system $\mathrm{Co}-\mathrm{Al}$ and in the cobalt / aluminum-rich portion of the ternary system $\mathrm{Co}-\mathrm{Ni}-\mathrm{Al}$. Z. Metallkunde, 87, 854-864.

Received 30.09.2013 